\title{
Minimally invasive plate osteosynthesis with dual plating for periprosthetic distal femoral fractures following total knee arthroplasty
}

Yong-Geun Park ${ }^{1 \dagger}$, Hyunseong Kang ${ }^{1 \dagger}$, Jung-Kook Song ${ }^{2}$, Jaehwang Lee ${ }^{1}$, Joseph Y. Rho ${ }^{1}$ and Sungwook Choi ${ }^{1^{*}}$ (D)

\begin{abstract}
Introduction: Adequate treatment for periprosthetic distal femur fractures is challenging because of various reasons, including severe osteoporosis and distal fragments that are too small or too distal. We have introduced a new surgical technique for dual plating of periprosthetic distal femur fractures following total knee arthroplasty (TKA) and determined the clinical and radiological outcomes of minimally invasive plate osteosynthesis (MIPO) with a dual locking compression plate (LCP).
\end{abstract}

Materials and methods: Between January 2010 and July 2019, 18 patients [mean age, 74.8 (68-89) years; average follow-up period, 14.8 (12-43) months] underwent MIPO with distal femoral LCP laterally and proximal humeral internal locking system (PHILOS) medially for periprosthetic distal femoral fractures following TKA. The minimum follow-up was 1 year. The clinical and radiological outcomes were assessed using the modified WOMAC scores, knee range of motion, time to callus formation, time to union, and complications of malunion, nonunion, and shortening.

Results: The average time to union was 18.4 weeks (range, 10-51 weeks) and to callus formation was 7.8 weeks (range, 2-14 weeks). At the 1-year follow-up, the average JLETS was 37.6 (range, 24-53), average knee ROM was $110.3^{\circ}$ (range, $80-135^{\circ}$ ), and average varus-valgus angles of the distal femur were $3.2^{\circ}$ (range, $-2.9^{-10.5^{\circ}}$ ). No nonunion, broken plates, or implant failure occurred. Malunion occurred in three patients.

Conclusion: MIPO with dual LCP is a reliable method for stabilizing periprosthetic distal femoral fractures following TKA, with satisfactory bone union rates and low complication rates.

Keywords: Periprosthetic distal femoral fractures, Total knee arthroplasty, Minimally invasive plate osteosynthesis, Dual locking compression plate

\footnotetext{
* Correspondence: swchoi1115@gmail.com

${ }^{\dagger}$ Yong-Geun Park and Hyunseong Kang contributed equally to the writing of this article.

'Department of Orthopaedic Surgery, Jeju National University School of Medicine, Aran 13gil 15, Jeju-si, Jeju, Self-Governing Province 63241, South Korea

Full list of author information is available at the end of the article
}

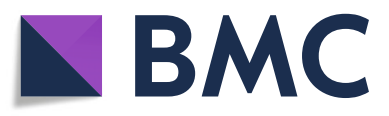

(- The Author(s). 2021 Open Access This article is licensed under a Creative Commons Attribution 4.0 International License, which permits use, sharing, adaptation, distribution and reproduction in any medium or format, as long as you give appropriate credit to the original author(s) and the source, provide a link to the Creative Commons licence, and indicate if changes were made. The images or other third party material in this article are included in the article's Creative Commons licence, unless indicated otherwise in a credit line to the material. If material is not included in the article's Creative Commons licence and your intended use is not permitted by statutory regulation or exceeds the permitted use, you will need to obtain permission directly from the copyright holder. To view a copy of this licence, visit http://creativecommons.org/licenses/by/4.0/ The Creative Commons Public Domain Dedication waiver (http://creativecommons.org/publicdomain/zero/1.0/) applies to the data made available in this article, unless otherwise stated in a credit line to the data. 


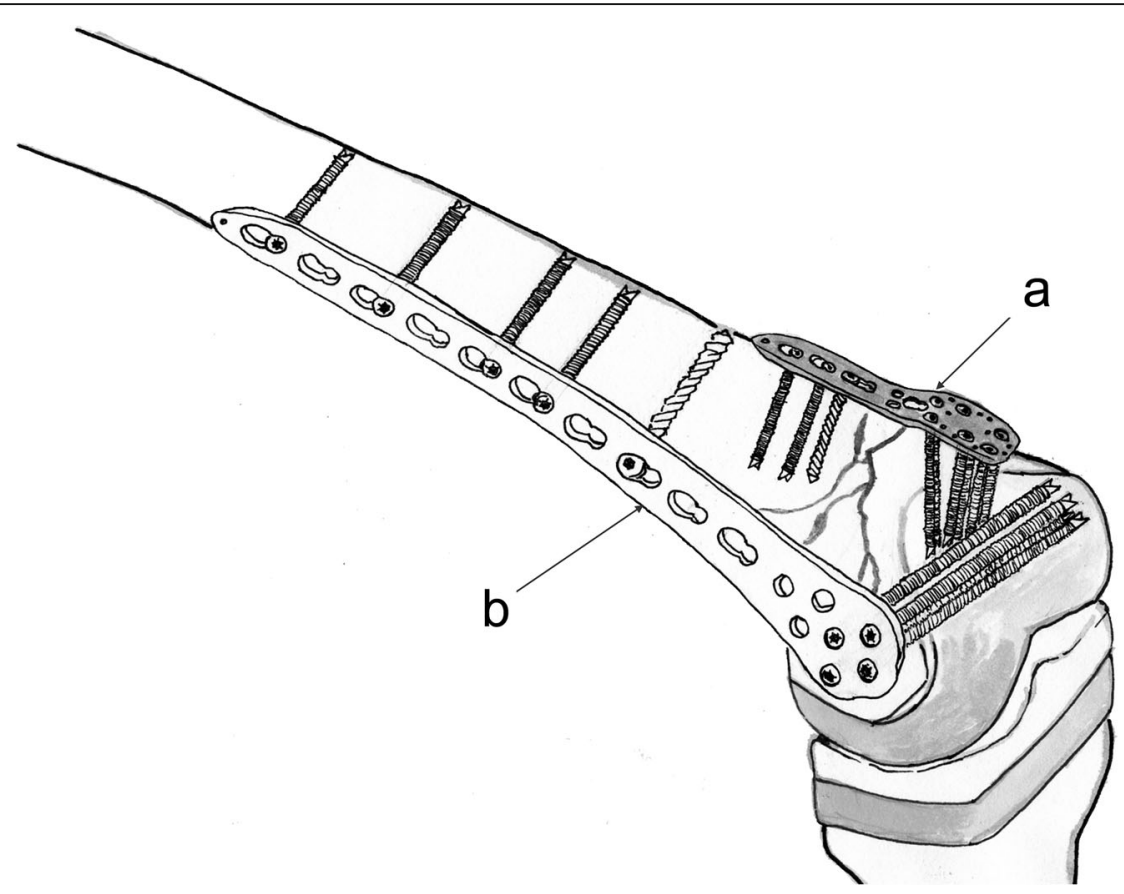

Fig. 1 Dual plating medially with (a) PHILOS plate and laterally with (b) distal femoral LCP for the periprosthetic fracture of the distal femur

\section{Introduction}

The incidence of periprosthetic distal femoral fractures following total knee arthroplasty (TKA) has been gradually increasing from 0.2 to $5.5 \%$ [1]. Risk factors include osteoporosis, female sex, elderly, rheumatoid arthritis, steroid use, and anterior femoral notching [2]. Selecting the most feasible treatment for these fractures is challenging because the severity of osteoporosis varies among patients and the amount of bone present for fixation is limited owing to the degree of comminution and distal extension of the fracture [3-5]. Periprosthetic fractures close to the implant have technical difficulties in firm fixation because

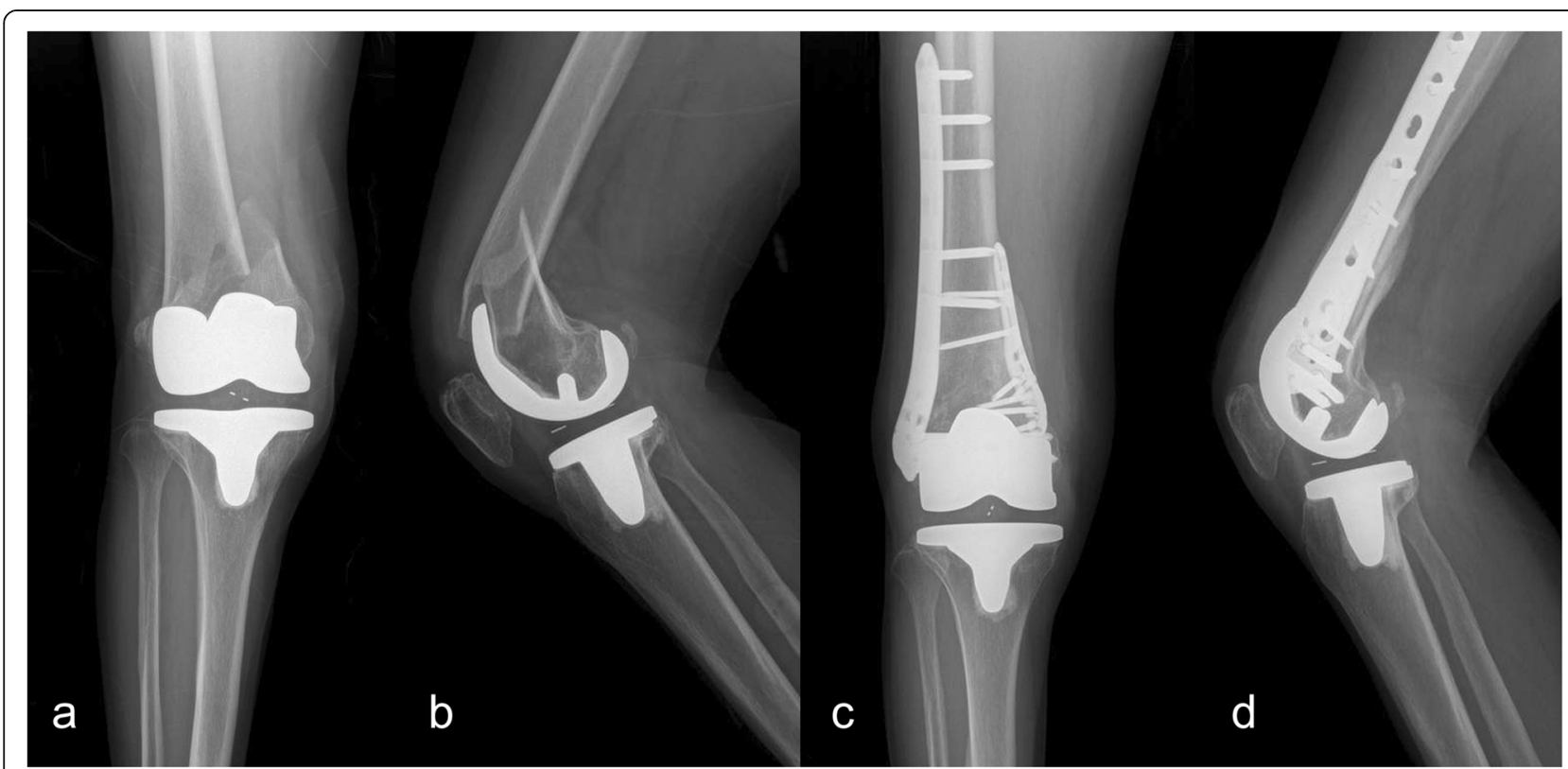

Fig. 2 Distal femoral periprosthetic fracture after slip-down in a 68-year-old female patient. a Preoperative knee AP and b lateral radiograph show Su classification type 2 in periprosthetic fracture of the distal femur. Minimally invasive plate osteosynthesis with dual LCP was performed. Post-operative 1-year knee ROM was $125^{\circ}$ and JLETS score was 42. c Post-operative knee AP and $\mathbf{d}$ lateral radiograph at 1 year show well-united fracture and satisfactory alignment 
of scarce bone fragments near the implant, which contributes to poor prognosis following TKA.

Various treatment options include conservative management, plate fixation, retrograde intramedullary nailing (IM), external fixation, and revisional arthroplasty [6-8]. To date, absolute stability has led to successful results $[3,7,9]$. Traditional plate fixation is highly likely to cause varus deformity and may not be feasible for very low distal femur periprosthetic fractures. Retrograde IM nailing has limited use owing to the implant design, as IM nails can pass through the intercondylar space. Distal lateral locking compression plate (LCP) used for the distal fragment increases the stability of the fracture site $[10,11]$. Lateral LCP plating for distal periprosthetic femur fractures versus revision arthroplasty for extremely distal cases is still controversial [12]. Sufficient stability has been observed with the recently introduced dual plating technique [13]. Additional medial plating had medial stability against varus collapse [14], but may also cause biologic disruption and muscular damage that can adversely affect bone union and post-operative range of motion (ROM).

This study aimed to evaluate the effects of MIPO with dual plating to treat periprosthetic distal femoral fractures following TKA (Fig. 1).

\section{Materials and methods}

\section{Patient selection}

Our institutional review board approved this study. We retrospectively reviewed the medical and radiological records of 18 patients [ 18 women; mean age, 74.8 years (68-89 years)] with periprosthetic distal femoral fractures treated using MIPO with distal femoral LCPs (Depuy Synthes, Oberdorf, Switzerland) laterally and proximal humeral internal locking system (PHILOS, Depuy Synthes, Oberdorf, Switzerland) medially (Fig. 2), between January 2010 and July 2019. According to the $\mathrm{Su}$ classification system [15] of periprosthetic fractures, type 1 was noted in two, type 2 in three, and type 3 in 13 patients. The average bone mineral density (BMD) was $-2.0(-4.3-0.3)$. Table 1 presents the demographic characteristics.

\section{Clinical and radiological evaluations}

Operative time, hospitalization days, time to callus formation, time to union, post-operative complications, and clinical performance were assessed by reviewing admission and outpatient medical records. Time to bone union and callus formation were evaluated by periodic radiologic studies. Patients were followed up at 1,3 , and 6 months and at 1 and 2 years post-operatively [average follow-up period, 14.8 months (range, 12-43 months)].

Clinical evaluation, including the knee ROM and modified Western Ontario McMaster Universities Index
Table 1 Demographic information

\begin{tabular}{|c|c|}
\hline Patient parameter & Value \\
\hline Mean age, (years) & $74.8 \pm 5.9(68-89)$ \\
\hline \multicolumn{2}{|l|}{ Sex, n (\%) } \\
\hline Male & $0(0.0)$ \\
\hline Female & $18(100.0)$ \\
\hline Body mass index $\left(\mathrm{kg} / \mathrm{m}^{2}\right)$ & $24.2 \pm 3.9(16.4-29.9)$ \\
\hline Bone mineral density(T-score) & $-2.0 \pm 1.2(-4.3-0.3)$ \\
\hline \multicolumn{2}{|l|}{ ASA $^{a}$ physical status class, $n(\%)$} \\
\hline I & $1(5.6)$ \\
\hline II & $15(83.3)$ \\
\hline III & $2(11.1)$ \\
\hline \multicolumn{2}{|l|}{ Operative side, $n$ (\%) } \\
\hline Left & $11(61.1)$ \\
\hline Right & $7(38.9)$ \\
\hline \multicolumn{2}{|l|}{ Su classification, n (\%) } \\
\hline Type I & $2(11.1)$ \\
\hline Type II & $3(16.7)$ \\
\hline Type III & $13(72.2)$ \\
\hline Operative time (minutes) & $146.2 \pm 44.8(92-255)$ \\
\hline Hospitalization days (days) & $45.9 \pm 32.6(6-123)$ \\
\hline Follow-up (months) & $14.8 \pm 10.2(12-43)$ \\
\hline Time to callus formation (weeks) & $7.8 \pm 3.5(2-14)$ \\
\hline Time to bone union (weeks) & $18.4 \pm 9.8(10-51)$ \\
\hline JLETS $^{b}$ & $37.6 \pm 8.5(24-53)$ \\
\hline Knee ROM ${ }^{c}$ & $110.3 \pm 15.7(80-135)$ \\
\hline Varus-valgus angle (degrees) & $3.2 \pm 3.3(-2.9-10.5)$ \\
\hline Shortening, n (\%) & $12(66.7)$ \\
\hline \multicolumn{2}{|l|}{ Complication, n (\%) } \\
\hline Malunion & $3(16.7)$ \\
\hline Nonunion & $0(0.0)$ \\
\hline
\end{tabular}

Note: Data presented as mean \pm standard deviation unless otherwise indicated

${ }^{a}$ American Society of Anesthesiologists, ${ }^{b}$ Jeju Lower Extremity Trauma Scale (the modified WOMAC), 'range of motion

of Osteoarthritis (WOMAC) score, was assessed at 1 year post-operatively. The modified WOMAC score (Jeju Lower Extremity Trauma Scale (JLETS)) comprises the following: pain, assessed by the visual analog scale (VAS) pain scoring system (10 points); activity score (30 points); ROM (10 points); and tenderness at the fracture site (5 points) [16].

Post-operative bone union and stability were assessed using routine anteroposterior (AP) and lateral radiographic views at each follow-up. Bone union was defined as bridging callus across the fracture site on both AP and lateral radiographs. The varus-valgus angle was 


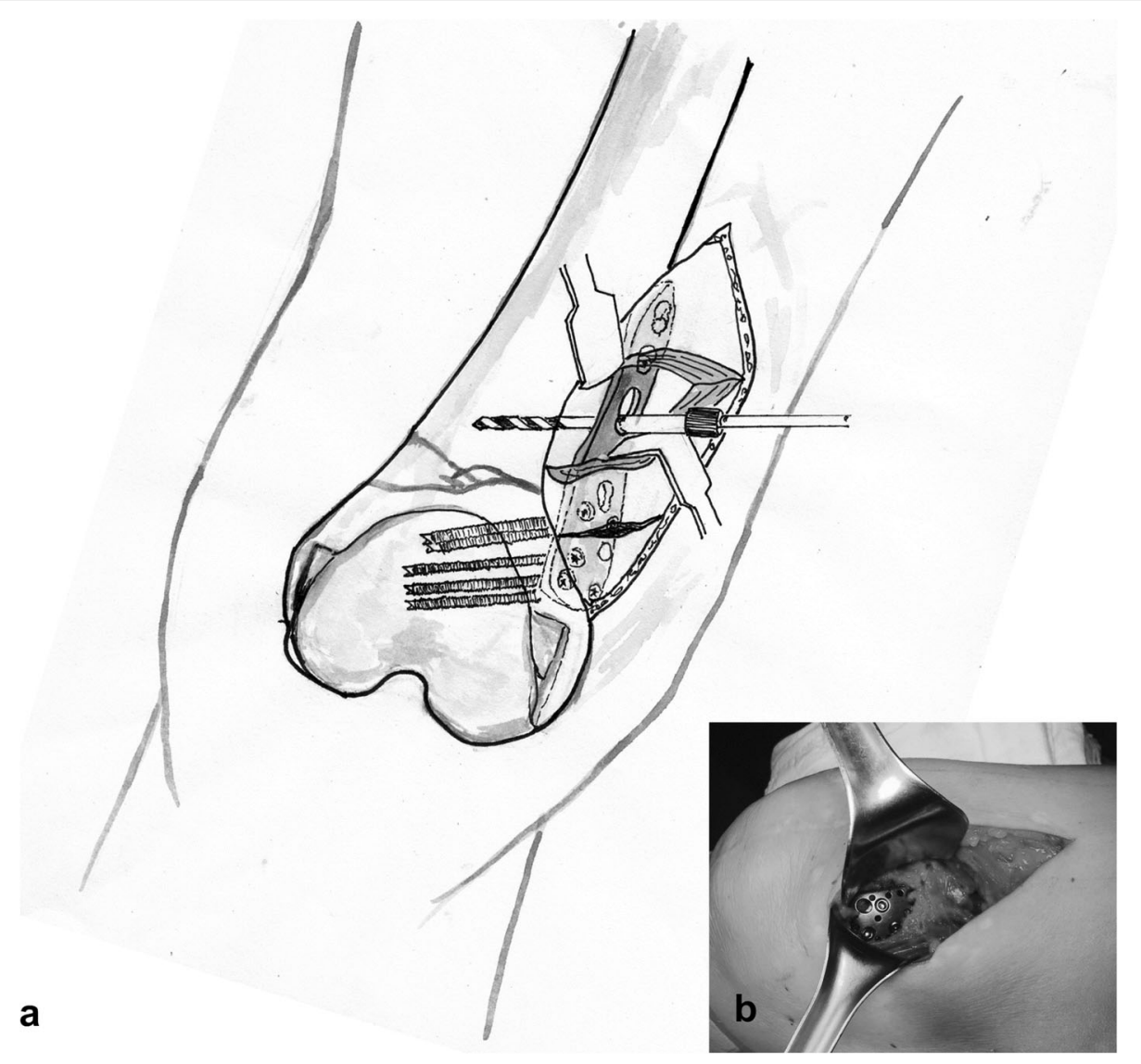

Fig. 3 Medial plating using the PHILOS plate. The purpose of medial plating is to offer better reduction of fracture and alignment. a The PHILOS plate is placed at the anteromedial aspect of the femur along the contour of the distal femur and fixated with a locking screw on bone fragments. Additional muscle dissection may be needed for proximal fixation because muscle incision is made along the obliquely running muscle fibers. $\mathbf{b}$ Gross photo image of medial plating is shown in a separate box

determined utilizing the femur shaft axis and femoral prosthetic horizontal line connecting the medial and lateral condyles on AP radiographs [17].

Nonunion was defined as lack of healing within 6 months. Malunion was defined as a coronal deformity (varus or valgus angulation) of $>5^{\circ}$, sagittal deformity (anterior or posterior angulation) of $>10^{\circ}$, rotational deformity of $>15^{\circ}$, and/or shortening of $>2 \mathrm{~cm}$.

The BMD of the normal hip was measured using dualenergy X-ray absorptiometry (Discovery; Hologic Inc., Bedford, MA, USA) post-operatively. The T-score of the femoral neck of the normal hip was selected as each patient's BMD. Body mass index was measured at the time of admission.

\section{Surgical technique}

Patients were positioned supine on the operating table under fluoroscopic guidance. The lower leg was draped from the iliac crest to the foot for intraoperative assessment of the length, rotation, and angulation. No tourniquets were utilized intraoperatively.

A longitudinal skin incision was made anteromedially to the distal femur. Vascular cauterization was strictly performed to prevent bleeding during dissection. The fracture site was exposed after dissecting the subcutaneous tissue and deep fascia of the vastus medialis (Fig. 3). Following careful reduction with a Joker elevator to avoid periosteal damage, AP and lateral fluoroscopic views confirmed accurate reduction. On obtaining satisfactory alignment, Kirshner wires (K-wires) and bone holding forceps were placed provisionally to maintain bi-planar fluoroscopic control. The PHILOS plate was placed on the anteromedial aspect of the distal femur to correspond with the distal femoral contour, and its proximal portion was positioned at the distal medial bone fragment for optimal screw fixation. K-wires and sleeve assemblies were used to confirm the final plate placement, one in the most proximal screw hole and one in 
the most distal screw hole for placement in the distal femur. Medial plating was finalized by fixation with locking screws in all fixable holes (Fig. 4).

After achieving reduction and stability to the best possible extent at the fracture site using medial plating, MIPO was performed using a distal femoral LCP for lateral plating (Fig. 5). The distal femoral LCP was selected according to the fracture location and configuration, and the plate was sufficiently long for the insertion of at least three screws at the proximal and distal mainframes. A longitudinal skin incision was made approximately $7 \mathrm{~cm}$ on the lateral aspect of the distal femur and the iliotibial band and vastus lateralis muscle were dissected along the direction of their fibers. A Cobb elevator was used for tunneling from the distal incision, and the LCP was inserted into the prepared tunnel. The proximal end of the plate was positioned at the center of the lateral cortex of the proximal femur without periosteal dissection. $\mathrm{K}$-wires and sleeve assemblies were used to evaluate the final placement of the plate, with one in the hole for the most proximal screw and one in the hole for the most distal screw to be placed in the femur. Cortical screws were fixed to reduce the space between the plate and femoral shaft. After locking screw placement at the distal portion of the plate, at least three locking screws were inserted in the proximal portion through small discrete skin incisions. The skin was closed in layers after irrigation, and a long leg splint was applied.

\section{Rehabilitation protocol}

Partial weight-bearing was allowed and continuous passive motion (CPM) of the knee and ankle were initiated on the second post-operative day. The CPM angle was adjusted according to each patient's tolerance. Full weight-bearing was permitted after the pain disappeared and callus formation was radiologically confirmed.

\section{Statistical analysis}

Statistical analysis was performed using SPSS for Windows 24.0 software package (SPSS Inc., Chicago, IL).

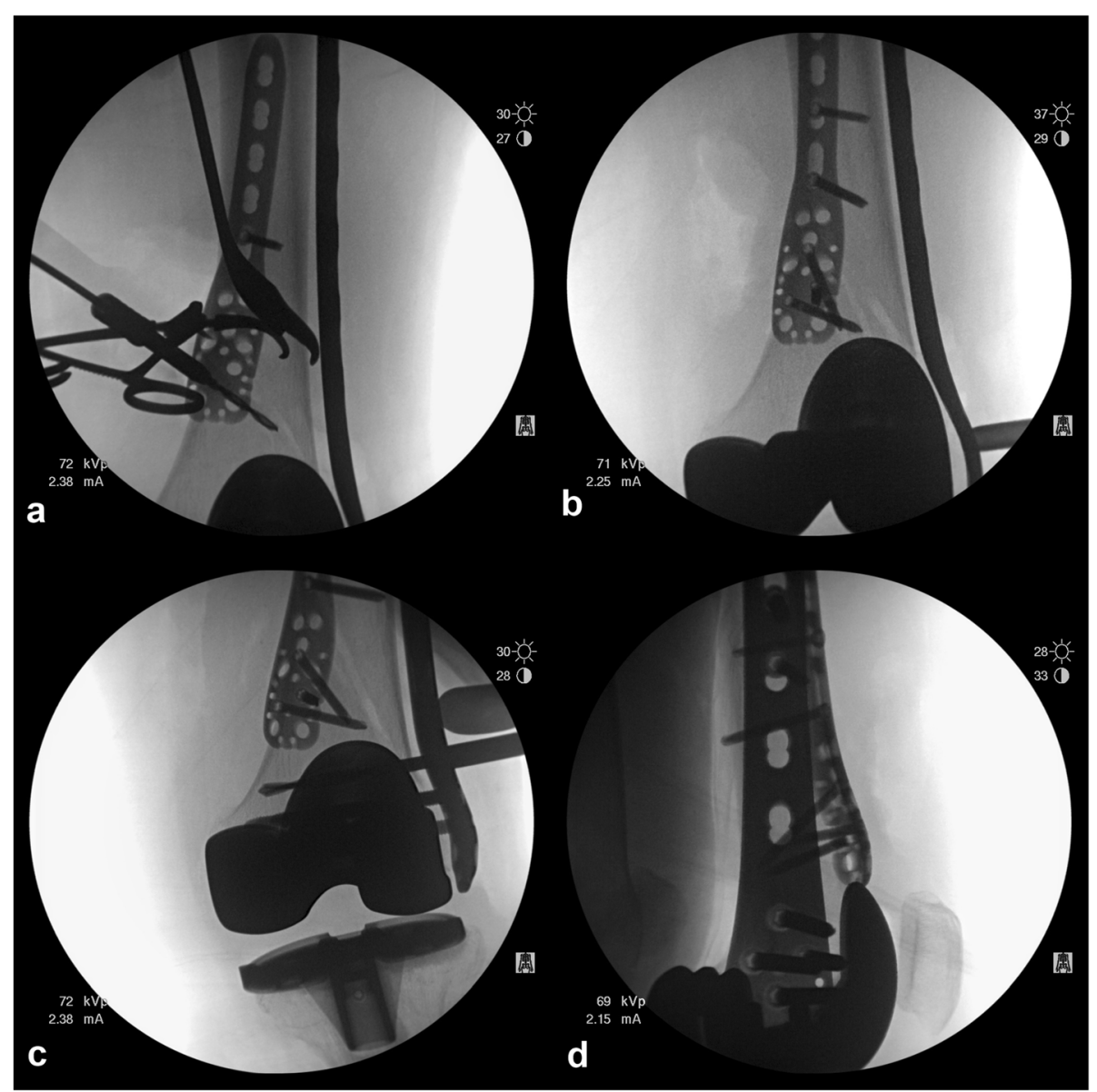

Fig. 4 Fluoroscopic intraoperative images showing a provisional fixation of fracture site with bone holding forceps and $\mathbf{b}$ the placement of the lateral LCP plate following medial PHILOS plate fixation. Once the anteromedial plate fixation is done and lateral LCP plate placement is checked, c, $\mathbf{d}$ remaining screw fixation is finalized 


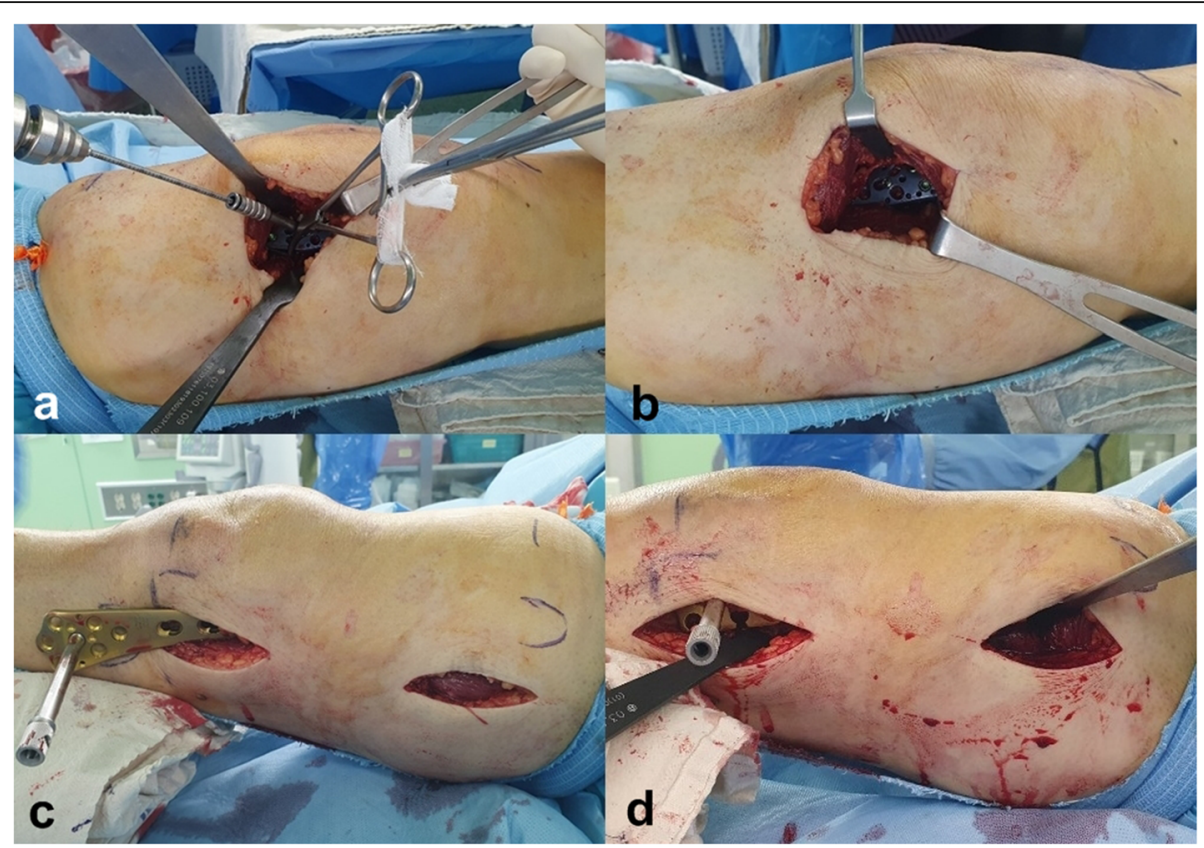

Fig. 5 Intraoperative images showing a, b provisional fixation and medial PHILOS plate fixation through anteromedial approach and $\mathbf{c}$, $\mathbf{d}$ fixation of lateral distal LCP plate using MIPO technique

Student's t-test was used for descriptive statistics of mean, standard deviation, frequency, and quantitative data. Fisher's exact chi-square test was used to evaluate radiographic outcomes. Spearman's rho correlation coefficient analysis was used to examine the relationships between other factors. Significance was set at $\mathrm{P}<0.05$.

\section{Results}

The average time to union was 18.4 weeks (range, 1051 weeks) and to callus formation was 7.8 weeks (range, 2-14 weeks).
At the 1-year follow-up, the average JLETS was 37.6 (range, 24-53) and the average knee ROM was $110.3^{\circ}$ (range, $80-135^{\circ}$ ). Fifteen patients $(83.3 \%)$ showed acceptable ROM of $>100^{\circ}$. No patient had difficulty in daily activities and domestic duties.

Severe valgus and flexion deformity of the distal femur on the initial AP and lateral radiographs were corrected by dual LCP plate fixation. One year post-operatively, the average varus-valgus angle of the distal femur was $3.2^{\circ}$ (range, $-2.9-10.5^{\circ}$ ). One patient had shortening.

Table 2 Comparison between osteoporosis patients and normal patients

\begin{tabular}{|c|c|c|c|c|}
\hline Patient parameter & $\mathrm{BMD}<-2.5(\mathrm{~N}=5)$ & $\mathrm{BMD} \geq-2.5(\mathrm{~N}=13)$ & Total $(\mathrm{N}=18)$ & $P$ \\
\hline Mean age, (years) & $75.4 \pm 7.0$ & $74.6 \pm 5.7$ & $74.8 \pm 5.9(68-89)$ & 0.809 \\
\hline Bone mineral density(T-score) & $-3.5 \pm 0.48$ & $-1.4 \pm 0.8$ & $-2.0 \pm 1.2(-4.3-0.3)$ & $<0.001$ \\
\hline Time to bone union (weeks) & $15.8 \pm 4.6$ & $19.5 \pm 11.1$ & $18.4 \pm 9.8(10-51)$ & 0.493 \\
\hline JLETS $^{\mathrm{a}}$ & $29.6 \pm 4.0$ & $40.7 \pm 7.7$ & $37.6 \pm 8.5(24-53)$ & 0.008 \\
\hline Varus-valgus angle (degrees) & $4.4 \pm 3.5$ & $2.7 \pm 3.2$ & $3.2 \pm 3.3(-2.9-10.5)$ & 0.347 \\
\hline Shortening, n (\%) & & & & $0.722^{b}$ \\
\hline Yes & $0(0.0)$ & $1(7.7)$ & $1(5.6)$ & \\
\hline No & $5(4.7)$ & $12(92.3)$ & $17(94.4)$ & \\
\hline Malunion, $\mathrm{n}(\%)$ & & & & $0.650^{\mathrm{b}}$ \\
\hline Yes & $1(20.0)$ & $2(15.4)$ & $3(16.7)$ & \\
\hline No & $4(80.0)$ & $11(84.6)$ & $15(83.3)$ & \\
\hline
\end{tabular}

Note: Data presented as mean \pm standard deviation unless otherwise indicated

${ }^{\mathrm{a}}$ Jeju Lower Extremity Trauma Scale (the modified WOMAC), ${ }^{\mathrm{b}}$ Fisher exact test 
No nonunion, broken plates, or implant failures were observed. Three patients had malunion. No revision operations were required during the study period.

In patients with osteoporosis (BMD $<-2.5)$, the JLETS was significantly reduced. However, there were no statistically significant differences in the other factors between osteoporotic and normal patients (Table 2).

In addition to the correlation between BMD and JLETS, bone union took longer in older patients (Table 3).

\section{Discussion}

In this study, we evaluated the effects of MIPO with dual plating to treat periprosthetic distal femoral fractures following TKA in 18 patients and found that MIPO with dual LCP is a reliable method for stabilizing periprosthetic distal femoral fractures following TKA, with satisfactory bone union rates and low complication rates.

Recent reports focusing on retrograde IM nailing and LCP plating support the priority of these two procedures over conventional plating $[8,10,15,18]$. The comparison of LCP plating and retrograde IM nailing showed no statistically significant differences with respect to nonunion rates. LCP plating showed significantly lower malunion rates than retrograde IM nailing in a systematic review [19], and the authors proposed three reasons for the superiority of the LCP over retrograde IM nailing for malunion rates. First, the starting point for retrograde IM nailing is dictated by the position of the femoral component and can cause malreduction. Second, retrograde IM nailing does not have the capacity to fill the wide metaphyseal intramedullary space, which allows for potential movement of the distal fragment relative to the nail. Third, the LCP plate offers more distal fragment fixation options than retrograde IM nailing.

The recently introduced dual plating technique with medial plate application for extremely distal periprosthetic fractures can provide sufficient stability [13]. In a biomechanical study, dual plating was more effective and had greater stability than simple lateral plating [14]. Medial plating is not widely attempted because of potential injury to the femoral artery. However, in a recent study, a medial plate could be safely applied on the anteromedial aspect of the distal femur to a distance of up to $8 \mathrm{~cm}$ distal to the lesser trochanter [20]. A recent cadaveric study has stated that the distal $60 \%$ of the femur is a safe zone for medial plating [21]. Hence, medial plating along with MIPO and lateral LCP plating is not only safe but also rigid enough to support a medial-sided fracture.

In a previous study that used double plating in different directions (orthogonal, i.e., lateral and anterior) [22], various types of periprosthetic fractures (around total hip replacement arthroplasty, TKA, and inter-prosthetic fractures) were assessed, while including only one case of periprosthetic distal femoral fracture following TKA. PHILOS plates have many advantages in medial fixation, including a similar shape to the contour of the medial condyle and a size that does not interfere with the femoral component of TKA. A previously reported limitation of medial plates is that they exert a fixing force mainly in the coronal plane. However, the fixing direction of the screw in the PHILOS plate is from the anteromedial to posterolateral direction, and this fixation force on the sagittal plane is additionally applied to the distal femur, which contributes to additional stabilization in the coronal plane and introduces new stability in the sagittal plane. This diagonal plating has two vectors applied in the coronal and sagittal planes. Additionally, with the use of the PHILOS plate, the application of many screws with various angles is possible and provides a rigid and stable fixation.

No direct evidence exists that malunited periprosthetic fractures post-TKA is associated with early component failure or wear; however, previous literature suggests that component malposition could cause such complications [23]. Malunion of these fractures also causes component malposition and hence may be related to component failure or wear. This can be resolved by MIPO with an LCP placed laterally and initial fracture fixation with a PHILOS plate medially for periprosthetic distal femoral fractures. Moreover, double plating with an anteromedial PHILOS plate offers additional stabilization in the coronal plane and introduces stability in the sagittal plane. Hence, this

Table 3 Evaluation of correlation between other factors

\begin{tabular}{llllll}
\hline & Age & BMD & Time to union & JLETS & Varus-valgus \\
\hline Age & 1.000 & & & & \\
BMD & -0.293 & 1.000 & & & \\
Time to union & $0.489^{*}$ & 0.151 & 1.000 & & \\
JLETS & -0.206 & $0.489^{*}$ & -0.076 & 1.000 & \\
Varus-valgus & 0.107 & -0.419 & 0.019 & -0.076 & 1.000 \\
Shortening & -0.114 & -0.186 & -0.449 & -0.208 & -0.084 \\
\hline
\end{tabular}

Spearman's rho correlation test: ${ }^{*} P<0.05$ 
technique could potentially reduce TKA component failure or wear after periprosthetic distal femur fractures.

Despite satisfactory outcomes, our study has some limitations. First, we included a small number of cases, as periprosthetic distal femoral fractures have a low incidence. Our small sample size may increase the possibility of incomplete documentation and the risk to miss significances. Second, this was a retrospective study with no control group; therefore, our results should be validated by larger studies in the future. A long-term prospective randomized control study with a larger scale is necessary to further evaluate the efficacy of the dual plate technique compared with a conventional single plate fixation. Such would aid in strengthening the significance of each sample group by implementing random allocation of each type of fixation method.

\section{Conclusion}

When treating technically difficult periprosthetic distal femur fractures following TKA, using a dual plating technique with a distal femur LCP laterally and a PHILOS plate medially increases the accuracy of reduction and stability at the fracture site. Anteromedial PHILOS plates can offer additive stabilization in both coronal and sagittal planes.

\section{Abbreviations}

TKA: Total knee arthroplasty; MIPO: Minimally invasive plate osteosynthesis; LCP: Locking compression plate; PHILOS: Proximal humeral internal locking system; IM: Intramedullary; ROM: Range of motion; BMD: Bone mineral density; WOMAC: Western Ontario McMaster Universities Index of Osteoarthritis; JLETS: Jeju Lower Extremity Trauma Scale; VAS: Visual analog scale; AP: Anteroposterior; K-wires: Kirshner wires; CPM: Continuous passive motion

\section{Acknowledgements}

Not applicable.

\section{Authors' contributions}

SC participated in designing the research and drafting the manuscript. YGP participated in designing the research and collecting the data. HK participated in designing the research and statistical analysis. JKS participated in the statistical analysis. $J$ participated in writing the manuscript. JYR participated in collecting the data, writing assistance, and proofreading. All the authors have taken a significant and crucial part in the preparation of the article and have read and approved the final version.

\section{Funding}

This work was supported by a research grant from the Jeju National University Hospital Research Fund of Jeju National University in 2019.

\section{Availability of data and materials}

The datasets used and/or analyzed during the current study are available from the corresponding author on reasonable request.

\section{Declarations}

\section{Ethics approval and consent to participate}

All procedures performed in studies involving human participants were in accordance with the ethical standards of the institutional and/or national research committee and with the 1964 Helsinki Declaration and its later amendments or comparable ethical standards. As the following study was performed retrospectively, formal consent was not required.

\section{Consent for publication}

Not applicable.

\section{Competing interests}

The authors declare that they have no competing interests.

\section{Author details}

${ }^{1}$ Department of Orthopaedic Surgery, Jeju National University School of Medicine, Aran 13gil 15, Jeju-si, Jeju, Self-Governing Province 63241, South Korea. ${ }^{2}$ Department of Preventive Medicine, Jeju National University School of Medicine, Jeju, South Korea.

Received: 14 October 2020 Accepted: 27 June 2021

Published online: 06 July 2021

\section{References}

1. Della Rocca GJ, Leung KS, Pape H-C. Periprosthetic fractures: epidemiology and future projections. J Orthop Trauma. 2011;25(Supplement 2):S66-70. https://doi.org/10.1097/BOT.0b013e31821b8c28.

2. Kim K-I, Egol KA, Hozack WJ, Parvizi J. Periprosthetic fractures after total knee arthroplasties. Clin Orthop Relat Res. 2006;446:167-75. https://doi.org/1 0.1097/01.blo.0000214417.29335.19.

3. Ritter MA, Faris PM, Keating EM. Anterior femoral notching and ipsilateral supracondylar femur fracture in total knee arthroplasty. J Arthroplasty. 1988; 3(2):185-7. https://doi.org/10.1016/S0883-5403(88)80085-8.

4. Cain PR, Rubash HE, Wissinger HA, McClain EJ. Periprosthetic femoral fractures following total knee arthroplasty. Clin Orthop Relat Res. 1986;208: 205-14.

5. Anakwe R, Aitken S, Khan L. Osteoporotic periprosthetic fractures of the femur in elderly patients: outcome after fixation with the LISS plate. Injury. 2008;39(10):1191-7. https://doi.org/10.1016/j.injury.2008.02.003.

6. Kregor P, Hughes J, Cole P. Fixation of distal femoral fractures above tota knee arthroplasty utilizing the Less Invasive Stabilization System (LISS). Injury. 2001:32:64-75. https://doi.org/10.1016/S0020-1383(01)00185-1.

7. Cordeiro EN, Costa RC, Carazzato JG, Silva JS. Periprosthetic fractures in patients with total knee arthroplasties. Clin Orthop Relat Res. 1990;252:182-9.

8. Kregor P, Stannard J, Zlowodzki M, Cole P, Alonso J. Distal femoral fracture fixation utilizing the Less Invasive Stabilization System (LISS): the technique and early results. Injury. 2001;32:32-47. https://doi.org/10.1016/S0020-1383 (01)00182-6.

9. DiGioia AM 3rd, Rubash HE. Periprosthetic fractures of the femur after total knee arthroplasty. A literature review and treatment algorithm. Clin Orthop Relat Res. 1991;271:135-42.

10. Ricci WM, Loftus T, Cox C, Borrelli J. Locked plates combined with minimally invasive insertion technique for the treatment of periprosthetic supracondylar femur fractures above a total knee arthroplasty. J Orthop Trauma. 2006;20(3):190-6. https://doi.org/10.1097/00005131-20060300000005.

11. Russell GV Jr, Smith DG. Minimally invasive treatment of distal femur fractures: report of a technique. J Trauma Acute Care Surg. 1999;47(4):799. https://doi.org/10.1097/00005373-199910000-00037.

12. Streubel PN, Gardner M, Morshed S, Collinge C, Gallagher B, Ricci W. Are extreme distal periprosthetic supracondylar fractures of the femur too distal to fix using a lateral locked plate? J Bone Joint Surg Br. 2010;92:527-34.

13. Kim W, Song JH, Kim J-J. Periprosthetic fractures of the distal femur following total knee arthroplasty: even very distal fractures can be successfully treated using internal fixation. Int Orthop. 2015;39(10):1951-7. https://doi.org/10.1007/s00264-015-2970-9.

14. Muizelaar A, Winemaker MJ, Quenneville CE, Wohl GR. Preliminary testing of a novel bilateral plating technique for treating periprosthetic fractures of the distal femur. Clin Biomech. 2015;30(9):921-6. https://doi.org/10.1016/j. clinbiomech.2015.07.008

15. Su ET, DeWal H, Di Cesare PE. Periprosthetic femoral fractures above total knee replacements. J Am Acad Orthop Surg. 2004;12(1):12-20. https://doi. org/10.5435/00124635-200401000-00003.

16. Choi S, Lee TJ, Kim S, Cho C, Shim S, Kang H. Minimally Invasive Plate Osteosynthesis (MIPO) technique for complex tibial shaft fracture. Acta Orthopædica Belgica. 2019;85(2):224-33. 
17. Kim J-B, Song I-S, Sun D-H, Choi H. The result of treatment of femoral periprosthetic fractures after total knee arthroplasty. J Korean Orthop Assoc. 2014;49(6):446-53. https://doi.org/10.4055/jkoa.2014.49.6.446.

18. Merkel KD, Johnson JE. Supracondylar fracture of the femur after total knee arthroplasty. J Bone Joint Surg Am. 1986;68(1):29-43. https://doi.org/10.21 06/00004623-198668010-00005

19. Herrera DA, Kregor PJ, Cole PA, Levy BA, Jönsson A, Zlowodzki M. Treatment of acute distal femur fractures above a total knee arthroplasty: systematic review of 415 cases (1981-2006). Acta Orthop. 2008;79(1):22-7. https://doi. org/10.1080/17453670710014716.

20. Ristevski B, Nauth A, Williams DS, Hall JA, Whelan DB, Bhandari M, et al. Systematic review of the treatment of periprosthetic distal femur fractures. $J$ Orthop Trauma. 2014;28(5):307-12. https://doi.org/10.1097/BOT. 0000000000000002.

21. Kim JJ, Oh HK, Bae J-Y, Kim JW. Radiological assessment of the safe zone for medial minimally invasive plate osteosynthesis in the distal femur with computed tomography angiography. Injury. 2014;45(12):1964-9. https://doi. org/10.1016/j.injury.2014.09.023.

22. Jiamton C, Apivatthakakul T. The safety and feasibility of minimally invasive plate osteosynthesis (MIPO) on the medial side of the femur: a cadaveric injection study. Injury. 2015;46(11):2170-6. https://doi.org/10.1016/j.injury.201 5.08.032.

23. Ritter MA, Davis KE, Meding JB, Pierson JL, Berend ME, Malinzak RA. The effect of alignment and BMl on failure of total knee replacement. J Bone Joint Surg Am. 2011;93(17):1588-96. https://doi.org/10.2106/JBJS.J.00772.

\section{Publisher's Note}

Springer Nature remains neutral with regard to jurisdictional claims in published maps and institutional affiliations.

Ready to submit your research? Choose BMC and benefit from:

- fast, convenient online submission

- thorough peer review by experienced researchers in your field

- rapid publication on acceptance

- support for research data, including large and complex data types

- gold Open Access which fosters wider collaboration and increased citations

- maximum visibility for your research: over $100 \mathrm{M}$ website views per year

At $\mathrm{BMC}$, research is always in progress.

Learn more biomedcentral.com/submissions 